\title{
Assessment of Consumption Habits and Attitude Regarding Sports Drinks, Sugar Sweetened Beverages and Aerated Soft Drinks in Children Involved in Organized Sports in New Delhi
}

\begin{abstract}
Mridula G and Urvashi B*
Department of Pedodontics and Preventive Dentistry, Maulana Azad Institute of Dental Sciences, India

*Corresponding author: Bhushan U, Department of Pedodontics and Preventive Dentistry, Maulana Azad Institute of Dental Sciences, BSZ Marg, New Delhi, India
\end{abstract}

Received: J une 22, 2017; Accepted: J uly 25, 2017;

Published: August 01, 2017

\begin{abstract}
Aim: To assess consumption pattern of Sports drinks, Sugar sweetened beverages and Aerated soft drinks and evaluate dental erosion among children involved in sports in New Delhi, India.

Design: A cross-sectional study was done to assess the consumption habits of sports drinks and soft drinks among children playing organized sports in New Delhi. The sample comprised of 300 children aged 6 to 18 years attending various sports training programs. A close-ended structured questionnaire was used to evaluate consumption patterns of young athletes. Intra oral examination was done to evaluate dental erosion and to understand the association with consumption habits of acidic drinks.

Results: The present study showed that $61 \%$ participants were not aware of what a "Sports drink" was and 30\% thought that they were good for oral health. Of all the participants, $20.3 \%$ consumed it once a day and $5.7 \%$ consumed it more than once a day. Sugar sweetened beverages and aerated soft drinks were consumed more than once a day by $49.4 \%$ and $43.7 \%$ subjects, respectively. Dental erosion was high among children who consumed sports drinks, aerated soft drinks and was statistically significant $(p<0.05)$.
\end{abstract}

Conclusion: Knowledge about sports drinks was inadequate which indicates an urgent need for preventive and promotive programs for children, coaches and parents in New Delhi, India.

Keywords: Sports drinks; Soft drinks; Aerated beverages; Dental erosion

\section{Abbreviations}

SSBs: Sugar Sweetened Beverages; SPSS: Statistical Package for Social Sciences

\section{Introduction}

Good oral health is crucial for successful performance in sports and for the overall well being of the child. Children who participate in strenuous sports require the highest levels of nutrition to meet the energy demands of their activities. Dental erosion is defined as the irreversible loss of dental hard tissues caused by a chemical process not involving bacteria [1]. Over the last two decades, tooth erosion has become a significant clinical problem [2,3]. Dental erosion in children involved in Sports is a growing concern due to the frequent ingestion of sports drinks [4]. Sports drinks are acidic drinks, like fruit juices and carbonated drinks, most of which have $\mathrm{pH}$ below 5.5, the critical $\mathrm{pH}$ for enamel demineralization to occur [2,5]. Additionally, they also have free sugars thus having potential to cause dental caries also. They are used primarily by athletes to provide carbohydrates, electrolytes and for fluid replacement. Sports drinks are becoming increasingly popular in children and adolescents to quench their thirst and provide extra energy to improve their performance in sports.
Increased consumption of sports drinks, aerated soft drinks and other Sugar Sweetened Beverages (SSBs) puts children at increased risk of dental erosion. The frequent intake of sports drinks and carbonated mineral water has been implicated in tooth erosion [6]. Unusual drinking habits such as swishing or holding acidic drinks in the mouth for prolonged periods have also been linked to dental erosion [7]. Apart from oral health risks, consumption of these acidic beverages has been linked to obesity, diabetes, cardiac problems and gout as well $[8,9]$.

Uninhibited advertising, promotion and unawareness of these Acidic drinks pose a big public health hazard. The marketing of these drinks has become a lucrative money minting industry. Easy availability of food vending machines and fast food restaurants further catalyze the uninterrupted intake of these harmful beverages. Children and adolescents engaged in organized sports are especially vulnerable to external influences due to lack of adequate knowledge.

There is limited literature on knowledge and consumption habits of acidic drinks in children involved in organized sports, especially in India. Few studies have examined the effect of consumption pattern (frequency, method and timing of consumption) of these drinks on dental erosion. In light of the lacunae in literature, the objectives of
Austin J Nutri Food Sci - Volume 5 Issue 2 - 2017 ISSN : 2381-8980 | www.austinpublishing group.com Urvashi et al. ( All rights are reserved 


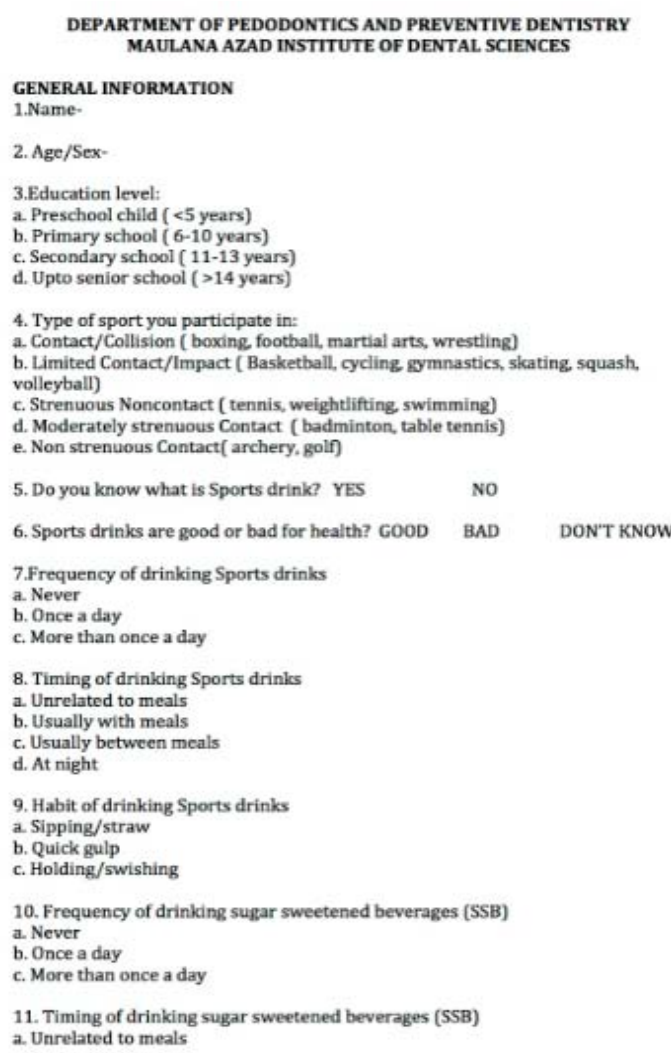

Figure 1: Questionnaire.

the present study were to (i) to assess the knowledge regarding sports drinks in children involved in organized sports; (ii) to evaluate the consumption habits of various acidic beverages and (iii) to investigate the relationship between consumption patterns of acidic drinks and dental erosion.

\section{Materials and Methods}

An observational, cross-sectional study was conducted at Indira Gandhi Sports Stadium in New Delhi, India. Ethical approval was obtained from the Institutional Ethics Committee prior to the commencement of the study. A sample of 300 children aged 6-18 years, who played different contact and non contact sports, were invited to participate in the study. Informed consent was obtained from all subjects prior to their participation in the study. Before the start of the study, the examiner was calibrated by a Pediatric Dentist Specialist at the Institute. The inter-examiner agreement was assessed using Kappa statistics which was found to be in the satisfactory range (85\% to $95 \%)$.

A close-ended structured questionnaire was exclusively developed for data collection and validated by a panel of experts. The questionnaire comprised of 15 items, with questions on type of sports played, knowledge about sports drinks, frequency of consumption of sports drinks, aerated soft drinks and SSBs, timing of consumption of these drinks and habits of drinking (Figure 1). The participants' gender, age, education level and sports activity were recorded. A basic intra oral examination was also carried out to evaluate the presence or absence of dental erosion and number of teeth involved in dental

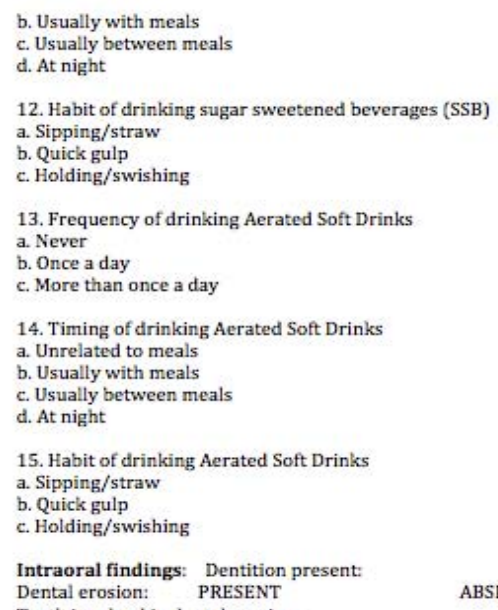

erosion. The clinical examination and recording of questionnaire was performed by single examiner the criteria from the Basic Erosive Wear Examination (BEWE) index for grading erosive wear was used [10]. Scores of $0,1,2$ and 3 were given for No erosive tooth wear, Initial loss of surface texture, Distinct defect with hard tissue loss $<50 \%$ of the surface area and Hard tissue loss $>50 \%$ of the surface area, respectively. The data was entered using MS Excel and statistical analysis was performed using SPSS (Statistical Package for Social Sciences, version 17). For the ease of statistical analysis, the scores for erosion were dichotomized as Present (Score 1, 2, 3) or absent (Score $0)$. Descriptive statistics were obtained for different variables and Chi-square test was applied to determine the relationship between consumption habits and dental erosion.

\section{Results}

\section{Distribution of participants}

The sample comprised of 300 children who were randomly selected from the sampling frame of children involved in different sports between the age group of 6-18 years. Among all the participants, 189 (63\%) were males and 111 (37\%) were females. Mean age of the participants was $12.19 \pm 3.38$ years. Out of the 300 participants, $163(54.3 \%)$ were engaged in limited impact/contact sports such as basketball, cycling and gymnastics while $52(17.3 \%)$ played moderately strenuous sports such as badminton, table tennis. Further, 72 (24\%) participants were involved in contact/collision sports such as boxing, wrestling and football and 13 (4.3\%) were involved in strenuous noncontact sports, such as tennis. The distribution of participants 




Figure 2: The distribution of participants in different sports.

Table 1: Relation of type of sport with gender.

\begin{tabular}{|c|c|c|c|}
\hline \multirow{2}{*}{ Type of Sport } & \multicolumn{2}{|c|}{ Gender } & \multirow{2}{*}{ Total } \\
\cline { 2 - 4 } & Male & Female & $163(54.3 \%)$ \\
\hline $\begin{array}{c}\text { Limited impact/ } \\
\text { contact }\end{array}$ & $95(50.3 \%)$ & $68(61.3 \%)$ & $52(17.3 \%)$ \\
\hline $\begin{array}{c}\text { Moderately } \\
\text { strenuous }\end{array}$ & $28(14.8 \%)$ & $24(21.6 \%)$ & $72(24.0 \%)$ \\
\hline $\begin{array}{c}\text { Contact/Collision } \\
\text { Strenuous } \\
\text { noncontact }\end{array}$ & $57(30.2 \%)$ & $15(13.5 \%)$ & $13(4.3 \%)$ \\
\hline Total & $189(100 \%)$ & $4(3.6 \%)$ & $300(100 \%)$ \\
\hline
\end{tabular}

in various sports is shown graphically in (Figure 2). The relation of Type of Sport played according to Gender is shown in (Table 1). Both males and females were involved maximally in limited impact/ contact sports. Males played more contact/collision sports compared to females while females outnumbered males in limited impact/ contact sports.

\section{Knowledge of Sports drinks}

Among all the participants, 183 (61\%) did not know what a "Sports drink" was. Further, 188 (62.7\%) participants were unaware if the "sports drink" was good or bad for health. Interestingly, 90 (30\%) participants reported that it was good for oral health, while only 22 (7.3\%) were aware that it was bad for oral health.

\section{Pattern of consumption habits}

In the present study, SSBs were the most frequently consumed drinks (83.3\%), followed by aerated soft drinks (65.7\%) and sports drinks (26.0\%) (Table 2).

Most typical patterns of consumption were for sports drinks to be consumed at any hour of the day unrelated to meals (73.0\%); SSBs between meals $(41.7 \%)$ and aerated soft drinks unrelated to meals (35.0\%). All the three types of drinks were consumed maximally by quick gulp. The consumption habits of the three drinks are shown in (Tables 2-4), respectively.

\section{Association between consumption habits and dental erosion}

Dental erosion was present in $8.3 \%$ ( $n=25$ subjects) of all the participants. A statistically significant association was observed
Table 2: Frequency of drinking different beverages.

\begin{tabular}{|c|c|c|c|}
\hline \multirow{2}{*}{$\begin{array}{c}\text { Frequency of } \\
\text { drinking }\end{array}$} & Sports drinks & $\begin{array}{c}\text { Sugar sweetened } \\
\text { beverages (SSBs) }\end{array}$ & Aerated soft drinks \\
\cline { 2 - 4 } & Frequency (\%) & Frequency (\%) & Frequency (\%) \\
\hline Never & $222(74.0 \%)$ & $50(16.7 \%)$ & $103(34.3 \%)$ \\
\hline $\begin{array}{c}\text { Once a day } \\
\text { More than once } \\
\text { a day }\end{array}$ & $61(20.3 \%)$ & $148(49.3 \%)$ & $66(22.0 \%)$ \\
\hline Total & 300 & $102(34.0 \%)$ & $131(43.7 \%)$ \\
\hline
\end{tabular}

Table 3: Time of drinking different beverages.

\begin{tabular}{|c|c|c|c|}
\hline \multirow{2}{*}{ Time of drinking } & Sports drinks & $\begin{array}{c}\text { Sugar sweetened } \\
\text { beverages (SSBs) }\end{array}$ & Aerated soft drinks \\
\cline { 2 - 4 } & Frequency (\%) & Frequency (\%) & Frequency (\%) \\
\hline Unrelated to meals & $219(73.0 \%)$ & $57(19.0 \%)$ & $105(35.0 \%)$ \\
\hline $\begin{array}{c}\text { Usually with meals } \\
\begin{array}{c}\text { Usually between } \\
\text { meals }\end{array}\end{array}$ & $26(8.7 \%)$ & $61(20.3 \%)$ & $24(8.0 \%)$ \\
\hline At night & $17(5.7 \%)$ & $57(19.0 \%)$ & $101(33.7 \%)$ \\
\hline Total & 300 & 300 & $30(23.3 \%)$ \\
\hline
\end{tabular}

Table 4: Method of drinking different beverages.

\begin{tabular}{|c|c|c|c|}
\hline \multirow{2}{*}{ Method of drinking } & Sports drinks & $\begin{array}{c}\text { Sugar sweetened } \\
\text { beverages (SSB) }\end{array}$ & Aerated soft drinks \\
\cline { 2 - 4 } & Frequency (\%) & Frequency (\%) & Frequency (\%) \\
\hline Sipping/straw & $112(37.3 \%)$ & $61(20.3 \%)$ & $71(23.7 \%)$ \\
\hline Quick gulp & $178(59.3 \%)$ & $136(45.3 \%)$ & $126(42.0 \%)$ \\
\hline Holding/swishing & $10(3.4 \%)$ & $103(34.4 \%)$ & $103(34.3 \%)$ \\
\hline Total & 300 & 300 & 300 \\
\hline
\end{tabular}

Table 5: Association between frequency and time of consumption of sports drinks and dental erosion.

\begin{tabular}{|c|c|c|}
\hline Variable & Dental erosion (\%) & p value \\
\hline $\begin{array}{c}\text { Frequency of } \\
\text { consuming sports } \\
\text { drinks }\end{array}$ & & \\
Never & & 0.001 \\
Once a day/More than \\
once a day
\end{tabular}

between the frequency of consumption of sports drinks and dental erosion $(\mathrm{p}=0.001)$. Also, the association between the time of consumption of sports drinks and dental erosion was statistically significant $(\mathrm{p}=0.001)$ as shown in (Table 5$)$.

Multivariate logistic regression analysis was done to see association between tooth erosion and other factors like age, gender, education level, and type of sport played, knowledge about Sports drink and consumption of various beverages (Table 6). Results show that children aged 14 and above, males, with education above secondary level, involved in contact sports, consuming SSB/Aerated soft drinks/Sports drink, drinking time unrelated to meals (for SSB, Sports drink), and those who knew what is Sports drink were more likely to have Dental erosion. 
Table 6: Multivariate logistic regression analysis showing association of different variables with tooth erosion.

\begin{tabular}{|c|}
\hline Variable Odds Ratio p value $95 \% \mathrm{Cl}$ \\
\hline $\begin{array}{c}\text { Age } \\
</=13 \text { years } \\
>/=14 \text { years } 5.550 .0001 * 2.23-13.8\end{array}$ \\
\hline $\begin{array}{c}\text { Gender } \\
\text { Male } 1.950 .160 .76-5.05 \\
\text { Female }\end{array}$ \\
\hline $\begin{array}{c}\text { Education level } \\
\text { Upto secondary level } \\
\text { Above secondary level } 4.75 \mathbf{0 . 0 0 1}^{*} 1.97-11.43\end{array}$ \\
\hline $\begin{array}{c}\text { Type of Sport } \\
\text { Contact } 1.490 .470 .49-4.52 \\
\text { Non-contact }\end{array}$ \\
\hline $\begin{array}{c}\text { SSB consumption } \\
\text { Consume } 0.780 .640 .27-2.19 \\
\text { Don't consume }\end{array}$ \\
\hline $\begin{array}{l}\text { Aerated drink consumption } \\
\text { Consume } 2.950 .05^{\star} 0.98-8.84 \\
\text { Don't consume }\end{array}$ \\
\hline $\begin{array}{l}\text { Sports drink consumption } \\
\text { Consume } 4.19 \text { 0.001* 1.81-9.69 } \\
\text { Don't consume }\end{array}$ \\
\hline $\begin{array}{c}\text { SSB drinking time } \\
\text { Related to meals } \\
\text { Unrelated to meals } 1.380 .50 \quad 0.52-3.64\end{array}$ \\
\hline $\begin{array}{c}\text { Aerated drinking time } \\
\text { Related to meals } 2.280 .100 .83-6.27 \\
\text { Unrelated to meals }\end{array}$ \\
\hline 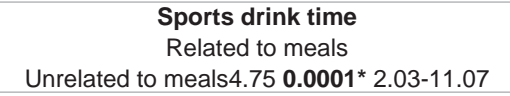 \\
\hline $\begin{array}{c}\text { Knowledge about Sports drink } \\
\text { Know } 7.34 \text { 0.0001* } 2.67-20.16 \\
\text { Don't know }\end{array}$ \\
\hline
\end{tabular}

$p>0.05=$ Non-significant $p<0.05^{\star}=$ Significant

\section{Discussion}

Persons involved in organized sports are prone to dehydration and loss of electrolytes, due to strenuous and long hours of training. To overcome this, they frequently indulge in sports drinks, energy drinks and various other carbonated drinks, which can have detrimental effects on oral and general health. Many of these drinks contain few nutrients and excess consumption can lead to dental erosion and tooth decay. In the present study, the authors assessed the knowledge about sports drinks in children and evaluated their consumption pattern of three acidic beverages - Sports drinks, SSBs and aerated soft drinks.

\section{Age of participants}

A large age group of 6-18 year old children was taken in the study. Dental erosion was seen more in children aged 14 and above, with education above secondary level. This may be due to higher consumption of acidic drinks under peer influence, taste, energy, hydration and the false belief that these drinks enhance performance in sports. Another study reported prevalence of sports drinks consumption in adolescents as high as $89 \%$, with $68 \%$ of children drinking them regularly (1-7 times a week) [11]. The frequency of consumption of sports drinks in this age group seem to have increased in recent years $[12,13]$.

\section{Type of sport played}

Children involved in contact sports reported more with dental erosion as compared to those playing non- contact sports. Contact sports involve high impact sports such as boxing, wrestling, football etc. These sports demanding more physical exertion leading to players consuming more of these acidic beverages.

The knowledge about sports drinks was poor in sports children as $61 \%$ of them were not aware what a sports drink was. Further, $62.7 \%$ of the children were unaware about the impact of such drinks on oral health. The participants consuming SSBs and aerated soft drinks were more $(83.3 \%$ and $65.7 \%$ respectively) when compared to those consuming sports drinks (26.0\%). A Statistically significant relationship was observed between the frequency of consumption of sports drinks, aerated drinks and dental erosion (Table 6). This was consistent with the results obtained by Lussi et al. (1991) and AlDlaigan et al. (2001) who also reported the direct association between consumption of sports drinks and dental erosion [14,12]. However, Mathew T et al. (2002) found no significant relationship between the consumption of sports drinks and dental erosion [15].

The association between SSBs and dental erosion was not statistically significant in the present study. This is in contrast to a number of epidemiological studies which have shown significant relationships between acidic drink consumption and erosion $[12,16,17]$. Jervinen VK et al. (1991) reported an apparent increase in the risk of erosion when sports drinks were consumed once or more per week, or when soft drinks were consumed daily [18].

Few researchers have suggested that the drinking habit, rather than the frequency of drinking is more critical to dental erosion. Soft drinks intake at meal times is less harmful than those consumed alone, and continuous sipping is more harmful to teeth than taking a drink at once in quick gulp [19]. Shellis RP et al. (2005) found that rapid erosion was seen when erosive drinks were consumed from a straw placed labial to the anterior teeth, or were "swished" between the teeth [20]. Johansson et al. (2004) compared the different methods of drinking and found holding the drink in the mouth before swallowing led to the most pronounced $\mathrm{pH}$ drop, followed by the long-sipping method. Gulping resulted in only a small decrease of $\mathrm{pH}$ in the above mentioned study [21]. Similarly, in the present study, the maximum number of participants was using quick gulp method to drink. This could probably be the reason for a lack of statistically significant association with dental erosion.

The time of drinking sports drinks and its association with dental erosion was statistically significant in the present study. The participants who were consuming sports drinks between meals or at any hour of the day correlated positively with dental erosion $(\mathrm{p}=0.001)$.

To the best of the authors' knowledge, the present study is the first of its kind conducted in the Indian population for the assessment of the impact of sports drinks on dental erosion. However, there were few limitations in the conduct of the present study. One of the limitations was recall bias with respect to the collection of data from the questionnaire. Also, the results of the current study might not be representative of every sports academy in New Delhi, due to differences in sports drink usage, individual preferences and lifestyle differences among children involved in sports. The present study indicated a significant need to promote the preventive programmes for sports children to improve their awareness regarding the acidic beverages. The preventive programmes could include prescription of a regular neutral sodium fluoride mouth rinse, limiting the intake of 
acidic drinks to meal times and relevant dietary advice [22]. More clinical studies involving the direct observation of tooth surfaces should be carried out to determine the strength of the associations between dental erosion and acidic drinks and consumption habits.

\section{Conclusion}

Within the limitations of the present study, it was concluded that the knowledge about sports drinks is deficient in the Indian scenario. This highlights the urgent need for preventive and promotive programs for children, coaches and parents in New Delhi, India. The production and sale of sports drinks is a lucrative and competitive industry, as evidenced by the rapidly growing variety of products, being marketed globally. Marketing strategies of sports drinks and other acidic drinks attract the young generation who are unaware about the related dental implications. Pediatric dentists have special responsibility to counsel children about the harmful effects of sports and soft drinks as it is an important yet overlooked aspect of sports dentistry. Oral health educators should reinforce the important practices to sports drinks users such as decreasing the time that the sports drink remains in the mouth and avoiding dehydration. Long term research and more number of in depth studies with larger sample size are required to determine the components in these drinks that are highly responsible for their erosive potential. Sports dentistry is an upcoming field and "sports drinks" is an important issue in it which should not be neglected.

\section{References}

1. Pindborg JJ. Pathology of dental hard tissues. Copenhagen: Munksgaard. 1970; 34: 175.

2. Milosevic A, Kelly MJ, McLean AN. Sports supplement drinks and dental health in competitive swimmers and cyclists. Br Dent J. 1997; 182: 303-308.

3. Harley K. Tooth wears in the child and the youth. Br Dent J. 1999; 186: 492 496.

4. Jarvinen VK, Rytomaa, Heinonen OP. Risk factors in dental erosion. J Dent Res. 1991; 70: 942-947.

5. Birkhed D. Sugar content, acidity and effect on plaque $\mathrm{pH}$ of fruit juices, fruit drinks, carbonated beverages and sport drinks. Caries Res. 1984; 18: $120-$ 127.

6. Milosevic A. Sport drinks hazard to teeth. Br J Sports Med. 1997; 31: 28-30.
7. Sirimaharaj $\mathrm{V}$, Brearley M, Morgan MV. Acidic diet and dental erosion among athletes. Australian Dental Journal. 2002; 47: 228-236.

8. Malik VS, Schulze MB, Hu FB. Intake of sugar-sweetened beverages and weight gain: a systematic review. Am J Clin Nutr. 2006; 84: 274-288.

9. Department of Nutrition at Harvard School of Public Health. Sugary Drinks and Obesity Fact Sheet. 2012.

10. Bartlett D, Ganss C, Lussi A. Basic Erosive Wear Examination (BEWE): a new scoring system for scientific and clinical needs. Clin Oral Invest. 2008; 12: S65-S68.

11. Broughton D, Fairchild RM, Morgan MZ. A survey of sports drinks consumption among adolescents. Br Dent J. 2016; 220: 639-643.

12. Al-Dlaigan $Y H$, Shaw L, Smith A. Dental erosion in a group of British 14- yearold school children. Part II: Influence of dietary intake. Br Dent J. 2001; 190: 258-261.

13. Bardsley PF, Taylor S. Epidemiological studies of tooth wear and dental erosion in 14-year old children in North West England. Part 2: The association of diet and habits. BDJ. 2004; 197: 479-483.

14. Lussi A, Schaffner M, Hotz $P$, Suter P. Dental erosion in a population of Swiss adults. Community Dent Oral Epidemiol. 1991; 19: 286-290.

15. Mathew T, Casamassimo PS, Hayes JR. Relationship between sports drinks and dental erosion in 304 university athletes in Columbus, Ohio, USA. Caries Res. 2002; 36: 281-287.

16. Millward A, Shaw L, Smith AJ, Rippin JW, Harrington E. The distribution and severity of tooth wear and the relationship between erosion and dietary constituents in a group of children. Int J Paediatr Dent. 1994; 4: 151-157.

17. O'Sullivan EA, Curzon ME. A comparison of acidic dietary factors in children with and without dental erosion. ASDC J Dent Child. 2000; 67: 186-192.

18. Shenkin JD, Heller KE, Warren JJ, Marshall TA. Soft drink consumption and caries risk in children and adolescents. Gen Dent. 2003; 51: 30-36.

19. Shellis RP, Finke M, Eisenburger M, Parker DM, Addy M. Relationship between enamel erosion and liquid flow rate. Eur J Oral Sci. 2005; 113: 232238.

20. Johansson AK, Lingström $P$, Imfeld T, Birkhed D. Influence of drinking method on tooth-surface $\mathrm{pH}$ in relation to dental erosion. Eur J Oral Sci. 2004; 112: 484-489.

21. Shaw L, Smith J. Dental erosion- the problem and some practical solutions. Br Dent J. 1998; 186: 115-118.

22. Milosevic A, Dawson IJ. Salivary factors in vomiting bulimics with and without pathological tooth wear. Caries Res. 1996; 30: 361-366.
Austin J Nutri Food Sci - Volume 5 Issue 2 - 2017

ISSN : 2381-8980 | www.austinpublishing group.com

Urvashi et al. (C) All rights are reserved
Citation: Mridula G and Urvashi B. Assessment of Consumption Habits and Attitude Regarding Sports Drinks, Sugar Sweetened Beverages and Aerated Soft Drinks in Children Involved in Organized Sports in New Delhi. Austin J Nutri Food Sci. 2017; 5(2): 1088 